\title{
Rickettsial infection in Amblyomma cajennense ticks and capybaras (Hydrochoerus hydrochaeris) in a Brazilian spotted fever-endemic area
}

Felipe S Krawczak ${ }^{1 *}$, Fernanda A Nieri-Bastos ${ }^{1}$, Fernanda P Nunes ${ }^{2}$, João F Soares ${ }^{1}$, Jonas Moraes-Filho ${ }^{1}$ and Marcelo B Labruna ${ }^{1 *}$

\begin{abstract}
Background: Brazilian spotted fever (BSF), caused by the bacterium Rickettsia rickettsii, is the deadliest spotted fever of the world. In most of the BSF-endemic areas, capybaras (Hydrochoerus hydrochaeris) are the principal host for the tick Amblyomma cajennense, which is the main vector of BSF.

Methods: In 2012, a BSF case was confirmed in a child that was bitten by ticks in a residential park area inhabited by A. cajennense-infested capybaras in Itú municipality, southeastern Brazil. Host questing A. cajennense adult ticks were collected in the residential park and brought alive to the laboratory, where they were macerated and intraperitoneally inoculated into guinea pigs. A tick-inoculated guinea pig that presented high fever was euthanized and its internal organs were macerated and inoculated into additional guinea pigs (guinea pig passage). Tissue samples from guinea pig passages were also used to inoculate Vero cells through the shell vial technique. Infected cells were used for molecular characterization of the rickettsial isolate through PCR and DNA sequencing of fragments of three rickettsial genes ( $g / t A, o m p A$, and ompB). Blood serum samples were collected from 172 capybaras that inhabited the residential park. Sera were tested through the immunofluorescence assay using R. rickettsii antigen.
\end{abstract}

Results: A tick-inoculated guinea pig presented high fever accompanied by scrotal reactions (edema and marked redness). These signs were reproduced by consecutive guinea pig passages. Rickettsia was successfully isolated in Vero cells that were inoculated with brain homogenate derived from a $3^{\text {rd }}$ passage-febrile guinea pig. Molecular characterization of this rickettsial isolate (designated as strain ITU) yielded DNA sequences that were all 100\% identical to corresponding sequences of R. rickettsii in Genbank. A total of 83 (48.3\%) out of 172 capybaras were seroreactive to $R$. rickettsii, with endpoint titers ranging from 64 to 8192 .

Conclusions: A viable isolate of $R$. rickettsii was obtained from the tick A. cajennense, comprising the first viable $R$. rickettsi isolate from this tick species during the last 60 years. Nearly half of the capybara population of the residential park was seroreactive to $R$. rickettsii, corroborating the findings that the local $A$. cajennense population was infected by $R$. rickettsii.

Keywords: Amblyomma cajennense, Rickettsia rickettsii, Brazilian spotted fever, Capybara

\footnotetext{
*Correspondence: felipekvet@gmail.com; labruna@usp.br

'Department of Preventive Veterinary medicine and animal Health, Faculty of Veterinary Medicine, University of São Paulo, São Paulo, SP 05508-270, Brazil Full list of author information is available at the end of the article
} 


\section{Background}

Brazilian spotted fever (BSF) is the deadliest spotted fever of the world. It has been reported in southeastern Brazil, where 591 laboratory-confirmed cases were reported from 1989 to 2008, resulting in 186 deaths (31.5\% fatality rate) [1]. In the state of São Paulo, the most populated of Brazil, a total of 555 cases were laboratory confirmed from 1985 to 2012, with 225 deaths (40.5\% fatality rate) (official data from the São Paulo State Health Office, available at http://www.cve.saude.sp.gov.br/htm/cve_fmb. html). The disease is caused by the bacterium Rickettsia rickettsii, which also causes severe cases of spotted fever in other American countries, including the United States, where the disease is called Rocky Mountain spotted fever (RMSF). In contrast to the high fatality rates of BSF in southeastern Brazil, RMSF has been reported at $5-10 \%$ fatality rates in the United States [2]. The reasons for such a contrast are still speculative; however, two studies have showed genetic differences between $R$. rickettsii strains from South and North Americas [3,4], highlighting the possibility that more virulent strains circulate in South America, as recently suggested by different authors [4-6].

In Brazil, $R$. rickettsii is considered to be transmitted to humans by two tick species: Amblyomma aureolatum in the metropolitan area of São Paulo [7], and by Amblyomma cajennense in the remaining BSF-endemic areas of southeastern Brazil [8,9]. In the metropolitan area of São Paulo, 1-10\% infection rates by $R$. rickettsii have been reported in $A$. aureolatum tick populations $[7,10]$. In these areas, $R$. rickettsii is considered to be successfully maintained in tick populations through very efficient transovarial and transstadial transmissions [11]. However, because $R$. rickettsii elicits some deleterious effect to $A$. aureolatum engorged females, horizontal transmission through the participation of amplifier vertebrate hosts for the formation of new lineages of infected ticks seems to be crucial in a long term scenario for maintenance of $R$. rickettsii in A. aureolatum populations [11]. Competent amplifier hosts are still unknown in the A. aureolatum transmission areas [7].

Similarly to that previously reported for A. aureolatum, the infection by $R$. rickettsii also elicits deleterious effects on $A$. cajennense engorged females [12]. However, $R$, rickettsii is not very efficiently maintained in $A$. cajennense populations through transovarial and transstadial transmissions, since less than $50 \%$ of the infected females pass the agent vertically, and when they do, less than $50 \%$ of the offspring become infected [12]. For this reason, the participation of vertebrate amplifier hosts to create new lineages of infected ticks, in order to avoid the disappearance of $R$. rickettsii from the tick population, is likely to be frequently needed in the A. cajennense-BSF transmission areas [12]. In this case, capybaras (Hydrochoerus hydrochaeris) have played a crucial role in BSF-endemic areas of southeastern Brazil $[8,12,13]$.
Besides being the most important host for all parasitic stages of $A$. cajennense in these endemic areas, capybaras are efficient amplifier hosts of $R$. rickettsii for $A$. cajennense ticks, as demonstrated in a recent study [14].

During the first half of the $20^{\text {th }}$ century, A. cajennense was first incriminated as a vector of $R$. rickettsii due to its epidemiological association with the BSF human cases, and because a number of $R$. rickettsii isolates were obtained from this tick species, through the inoculation of tick homogenates into guinea pigs [15-18]. Since then, no additional viable isolates of $R$. rickettsii have been obtained from A. cajennense. While a few recent studies detected $R$. rickettsii DNA in $A$. cajennense ticks [9,19], several other ones failed to detect a single $R$, rickettsii-infected tick by molecular methods among hundreds to thousands of A. cajennense ticks collected from BSF-endemic areas [20-23]. These findings corroborate the above mentioned experimental studies, which showed that $A$. cajennense is not very efficient to sustain a $R$. rickettsii infection, and for this reason, finding a $R$. rickettsii-infected $A$. cajennense tick has been a very difficult task. Even under such circumstances, $A$. cajennense still assumes a major role as vector of $R$. rickettsii to humans just because this tick is the most common human-biting tick in southeastern Brazil, where humans are frequently infested by dozens to hundreds of individuals in each infestation episode [20,24,25].

In the present study, we investigated the circulation of $R$. rickettsii among capybaras and ticks in one area where a laboratory-confirmed case of BSF had just occurred. During the study, we obtained a viable isolate of $R$. rickettsii from A. cajennense ticks, comprising the first isolate established from this tick species during the last 60 years.

\section{Methods}

\section{Study area and tick collection}

This study was performed in a residential park area at Itú Municipality, state of São Paulo, southeastern Brazil. The residential park had an area of 484 ha, which contained four lakes, and $\approx 400$ homes interposed by conserved forest areas. In September 2012, a severe case of BSF occurred in a child few days after being infested by ticks while playing near one of the lakes of the residential park, inhabited by free-ranging capybaras. After two weeks under hospitalization and therapy with chloramphenicol, the child had the infection resolved. In October 2012, we visited the residential park for collection of free-living ticks by using $20 \mathrm{CO}_{2}$ traps armed at capybara common places (including the site where the child got tick-infested) as previously described [26]. Thousands of Amblyomma unfed nymphs, and hundreds of Amblyomma unfed adult ticks were captured by the $\mathrm{CO}_{2}$ traps. Only adult ticks were taken alive to the laboratory, where they were incubated at $35^{\circ} \mathrm{C}$ and $95-100 \%$ 
relative humidity for 48 hours, prior to being processed for rickettsial isolation.

\section{Isolation of rickettsiae}

After incubation for $48 \mathrm{~h}$ in the laboratory, live adult ticks were counted, identified to species, and separated into $660 \mathrm{~A}$. cajennense and 42 Amblyomma dubitatum ticks. The $660 \mathrm{~A}$. cajennense ticks were used to form 7 pools; 6 pools contained 100 ticks, 1 pool contained 60 ticks. The $42 \mathrm{~A}$. dubitatum ticks formed a single pool. Ticks of each pool, still alive, were disinfected for $10 \mathrm{~min}$ in iodine alcohol, followed by several washes in sterile water, and then macerated all together into brain-heart infusion broth (BHI) in a sterile mortar with the aid of a sterile alundum. The resultant tick homogenate $(\approx 7 \mathrm{~mL})$ was inoculated intraperitoneally into an adult male guinea pig. Since we had 8 tick pools, we used 8 guinea pigs, one per tick pool. Guinea pigs had their rectal temperature measured daily until the 21st day post inoculation (DPI), when they were bled through cardiac puncture, and their sera were individually tested for the presence of anti- $R$. rickettsii antibodies through the immunofluorescence assay (IFA) using $R$. rickettsii antigen, as previously described [12]. If any of the tick-inoculated guinea pigs presented high fever (rectal temperature $>40.0^{\circ} \mathrm{C}$ ) for 3 consecutive days within the 21-day period, it was euthanized at the $3^{\text {rd }}$ febrile day and its internal organs (liver, spleen, lungs, brain) were macerated into BHI and the resultant homogenate was inoculated into additional guinea pigs (guinea pig passage). This procedure was repeated with additional guinea pigs; in each guinea pig passage, samples of the internal organs were frozen directly at $-80^{\circ} \mathrm{C}$, and then in liquid nitrogen, in order to cryopreserve the isolate before it could be adapted to in vitro tissue culture.

BHI-brain homogenate obtained from a 3rd passagefebrile guinea pig was divided into four $200 \mu \mathrm{l}$ aliquots; each one was inoculated into one shell vial containing a monolayer of confluent Vero cells, as previously described [27]. After inoculation, the shell vials were centrifuged for $1 \mathrm{~h}$ at $700 \mathrm{~g}$ and $22^{\circ} \mathrm{C}$. Then the monolayer was washed once with Roswell Park Memorial Institute medium (RPMI; Gibco, Carlsbad, CA) containing 10\% bovine calf serum (Hyclone, Logan, UT) and subsequently incubated at 28 or $34^{\circ} \mathrm{C}$ (two shell vials at each temperature). Every 3 days, the medium was switched to new medium, and the aspirated medium was checked by Giménez staining for the presence of Rickettsia-like organisms. If the result was positive, the monolayer of the shell vial was harvested and inoculated into a $25-\mathrm{cm}^{2}$ flask containing a monolayer of confluent uninfected Vero cells. Cells in the $25-\mathrm{cm}^{2}$ flask were checked by Giménez staining until $>90 \%$ of them were infected, when they were harvested and inoculated into $75-\mathrm{cm}^{2}$ flasks of Vero cells. The level of infection of cells was monitored by Giménez staining of scraped cells from the inoculated monolayer. The rickettsial isolate was considered to be established in the laboratory after at least three passages through $75-\mathrm{cm}^{2}$ Vero cell flasks, each achieving a proportion $>90 \%$ of infected cells [28].

For molecular characterization of the rickettsial isolate, DNA from the third infected cell passage was extracted by using the DNAeasy Blood and Tissue Kit (Qiagen, Valencia, California), and tested by a battery of different PCR protocols, with two primer pairs (CS-78 and CS-323; CS-239 and CS-1069) targeting two overlapping fragments of the rickettsial gltA gene [28], primers Rr190.70 F and Rr190.701R targeting a portion of the rickettsial ompA gene [29], and primers 120.M59 and 120-807 targeting a portion of the rickettsial $о т p B$ gene [30]. All PCR products were DNA sequenced, and the resultant sequences were compared with GenBank data by BLAST analysis.

\section{Capybaras}

Because the $A$. cajennense population of the residential park was sustained primarily by capybaras (no other important host for this tick species, such as horses, tapirs or pigs, was present in the area), the residential park was legally authorized to cull its entire capybara population with the aim to reduce the $A$. cajennense population to minimal levels within the residential park area. For this purpose, from December 2012 to May 2013, a total of 172 capybaras were collected by corrals according to Moreira et al. [31], and before been culled, individual blood samples were collected and sent to the laboratory for serological analysis. Capybara sera were individually tested through the IFA using $R$. rickettsii antigen, as previously described [14]. Briefly, capybara sera were diluted in 2-fold increments with phosphate-buffered saline (PBS), starting from the 1:64 dilution. A fluorescein isothiocyanate-labeled sheep anti-capybara IgG (CCZ, São Paulo/SP, Brazil) was used as conjugate. For each sample, the endpoint IgG titer reacting with $R$. rickettsii strain Taiaçu crude antigen was determined. In each slide, a serum previously shown to be nonreactive (negative control) and a known reactive serum (positive control), both from the study of Souza et al. [14], were tested at the 1:64 dilution. The proportions of seroreactive capybaras were compared between three age categories (infant, juvenile, or adult) and gender (male or female) by the Chi-square test. Values were considered significant at $P<0.05$.

\section{Ethical approval}

This work was authorized by the Environment State Secretary of the state of São Paulo (authorization no. 96/2012) and was approved by the Ethical Committee 
of Animal Use of the Faculty of Veterinary Medicine of the University of São Paulo (protocol No. 3104/2013).

\section{Results}

Among the 8 guinea pigs inoculated with adult tick homogenate, 2 animals (one inoculated with 100 A. cajennense, and one inoculated with $60 \mathrm{~A}$. cajennense) died in less than 24 hours, and were discarded from the study. Among the remaining 6 guinea pigs (each of 5 inoculated with 100 A. cajennense ticks; 1 inoculated with 42 A. dubitatum), only one (inoculated with $A$. cajennense) presented high fever at the $3^{\text {rd }}$ DPI, which persisted until the $5^{\text {th }}$ DPI, when the animal was euthanized and its internal organs were used to inoculate 3 additional guinea pigs, which all developed high fever starting at 3-5 DPI. These animals were euthanized at the $3^{\text {rd }}$ febrile day and their internal organs were used to inoculate 2 additional guinea pigs. A total of 4 guinea pig passages was performed, totaling 9 inoculated guinea pigs, which all developed high fever $\left(>40.0^{\circ} \mathrm{C}\right)$ that started 3 to 6 DPI. In all cases, fever was accompanied by scrotal reactions (edema and marked redness); a single guinea pig from the 3rd passage was not euthanized; in this case, the animal presented high fever from the $5^{\text {th }}$ to the $9^{\text {th }}$ DPI. When this animal was tested by serology at the 21th DPI, it presented a 8,192 endpoint titer to $R$. rickettsii. The remaining guinea pigs that were prima rily inoculated with tick homogenate (each of 4 inoculated with 100 A. cajennense, 1 inoculated with 42 A. dubitatum) remained afebrile (rectal temperature $<39.5^{\circ} \mathrm{C}$ ) until $21 \mathrm{DPI}$, when they were bled and were shown to be seronegative to $R$. rickettsii.

Rickettsiae were successfully isolated in Vero cells that were inoculated with brain homogenate derived from a $3^{\text {rd }}$ guinea pig passage of the A cajennense rickettsial isolate. A total of four Vero cell passages has been done, always resulting in $100 \%$ infected cells 5 to 8 days after inoculation of the monolayer. The rickettsial isolate was designated as strain ITU. DNA of strain ITU-infected cells at third passage was subjected to a battery of PCR protocols, which successfully amplified fragments of the rickettsial genes gltA, ompA, and ompB. We sequenced 1068, 590, and 763 nucleotides of the gltA, ompA, and $о т p B$ genes, respectively, which all showed $100 \%$ identity to corresponding sequences in the $R$. rickettsii genomes from Brazil [GenBank: CP003305] and Colombia [GenBank: CP003306]. The GenBank nucleotide sequence accession numbers of the partial sequences of $R$. rickettsii strain ITU generated in this study are KF742602 for the gltA gene, KF742603 for the ompA gene, and KF742604 for the $о m p B$ gene.

A total of 172 capybaras were sampled in the residential park. From these, 83 (48.3\%) were seroreactive to $R$. rickettsii antigens. The proportions of seroreactive animals were statistically similar among different age groups (Table 1). Similarly, the proportions of seroreactive animals were statistically similar between male $(46 / 85 ; 54.1 \%)$ and female $(37 / 87 ; 42.5 \%)$ capybaras (chi-square: 1.87 ; d.f. 1 ; $P=0.17)$. Seroreactive capybaras presented endpoint titers to $R$. rickettsii ranging from 64 to 8192 . The most frequent endpoint titer was 256 for infant animals, 1024 and 2048 for juveniles, and 512 for adult capybaras (Figure 1).

\section{Discussion}

A viable isolate of $R$. rickettsii was obtained from the tick A. cajennense collected from a BSF-endemic area. To achieve such results, we initially performed intraperitoneal inoculation of tick homogenate into guinea pigs, a method that was widely used during the first half of the $20^{\text {th }}$ century, when all previous isolates of $R$. rickettsii from A. cajennense were achieved [15-18,32-34]. With such procedure, we were able to sample hundreds of ticks with relatively few efforts, if compared to more contemporary methods that usually test ticks individually or in pools of few specimens by inoculating cell culture, such as the shell vial technique $[28,35,36]$. Indeed, the increasing use of the shell vial technique has allowed isolation of various Rickettsia species that could not be isolated by inoculation of guinea pigs with field-collected samples, just because most of the Rickettsia species are not pathogenic for this animal species [37]. On the other hand, because guinea pig inoculation remains an efficient and simple method for isolation of $R$. rickettsii from field-collected ticks, it should be adopted in more studies in Latin America, where $R$. rickettsii remains as the agent of a neglected, deadly bacterial disease. In fact, at least two recent studies have used guinea pig inoculation of patient samples for confirmatory diagnostic of RMSF fatal cases in Colombia and Costa Rica [38,39].

Only one guinea pig, inoculated with 100 A. cajennense adult ticks, developed rickettsiosis that was shown to be caused by $R$. rickettsii. This result indicates that at least one $R$. rickettsii-infected tick was present in the tick pool that was used to inoculate this guinea pig. Because other 4 guinea pigs, each inoculated with $100 \mathrm{~A}$. cajennense, remained afebrile and seronegative during the study, we

Table 1 Number of capybaras seroreactive to Rickettsia rickettsii according to age category

\begin{tabular}{lll}
\hline Age category & No. tested & No. seroreactive (\%) \\
\hline Infant & 62 & $29(46.8) a$ \\
Juvenile & 35 & $13(37.1) \mathrm{a}$ \\
Adult & 75 & $41(54.7) \mathrm{a}$ \\
Total & 172 & $83(48.3)$ \\
\hline
\end{tabular}

a: the proportions of seroreactive animals were not significantly different between age categories (chi-square: 3.02; d.f. 2; $P=0.22$ ). 


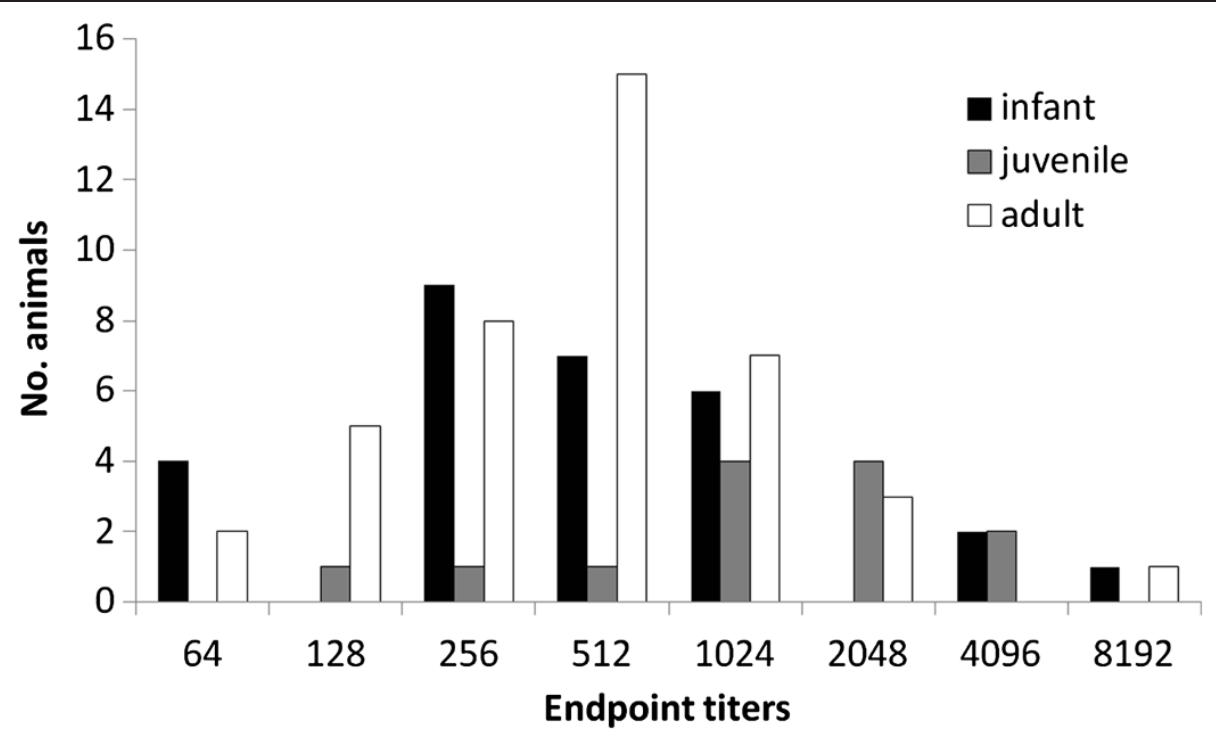

Figure 1 Anti-Rickettsia rickettsii endpoint titers of IgG antibodies in capybaras of three age groups (infant, juvenile, and adult) from a residential park at Itu Municipality, state of São Paulo, Brazil.

can infer a minimal infection rate of $0.2 \%(1 / 500)$ for the A. cajennense population tested in the present study. This low rate is quite expected since several recent studies have failed to detect $R$. rickettsii-infected ticks from BSFendemic areas [20-23], whereas two other studies performed in one endemic area detected $R$. rickettsii DNA in at least $1(1.28 \%)$ out of $78 \mathrm{~A}$. cajennense ticks collected during 2003-2004, and 2 (0.5\%) out of 400 A. cajennense ticks collected during 2006-2008 [9,19]. Since human infestation by $A$. cajennense is very common in southeastern Brazil [20,25], very low $R$. rickettsii-infection rates among $A$. cajennense populations from BSF-endemic areas should be a major reason for the low incidence of the disease (usually 0.1 case per 100,000 persons) in these areas [40].

For the present study, we collected unfed ticks from the environment and incubated them at $35^{\circ} \mathrm{C}$ for $48 \mathrm{~h}$ prior to guinea pig inoculation. This procedure was adopted because previous studies reported that injection of triturated, unfed, $R$. rickettsii-infected ticks into guinea pigs did not lead to disease, but caused seroconversion. However, feeding the ticks for a short time or keeping them at an elevated temperature $\left(24-48 \mathrm{~h}\right.$ at $35-37^{\circ} \mathrm{C}$ before trituration and inoculation into non-immune guinea pigs) resulted in clinically manifest disease [41-43]. Finally, this incubation at higher temperature for $48 \mathrm{~h}$ might also have induced rickettsial multiplication within ticks [44], and therefore, enhanced the chances of rickettsial isolation, especially because we worked with pools of up to 100 unfed ticks.

The 172 capybaras tested by serology represented at least $90 \%$ of the whole capybara population of the residential park. Nearly half of this capybara population was seroreactive to $R$. rickettsii, similarly to what has been found in other BSF-endemic areas, where $40-100 \%$ of horses or capybaras (main hosts of $A$. cajennense) have been found to be seroreactive to $R$. rickettsii $[20,45,46]$. In a recent study [14], capybaras experimentally infected with $R$. rickettsii via infected $A$. cajennense ticks developed high antibody endpoint titers $(8,192-32,768)$ from 30 to 146 days post infestation. Because at least two capybaras of the present study also showed high antibody endpoint titers (8192) (Figure 1), we can infer that they were exposed to $R$. rickettsii-infected ticks during few months prior to being sampled. On the other hand, capybaras with lower antibody titers could be in a phase of ascending (recent infection) or descending (earlier infection) antibody titers to $R$. rickettsii. Finally, the overall lower titers observed in infant capybaras of the present study could be related to passive immunity, whereas overall higher endpoint titers in juvenile and adult capybaras could be related to a past active immunity elicited by transmission of $R$. rickettsii by ticks.

The fact that nearly half of the capybara population of the residential park was seronegative to $R$. rickettsii means that new lineages of infected ticks could be created in a short term, as susceptible animals would develop rickettsemia after a primary infection via infected ticks. Therefore, the procedure of the residential park to cull its entire capybara population was reasonable, in order to prevent new human cases of BSF in the area, where no other host species (i.e., horses, tapirs, pigs) that could sustain a $A$. cajennense population was present. 


\section{Conclusions}

A viable isolate of $R$. rickettsii was obtained from the tick A. cajennense, comprising the first viable $R$. rickettsi isolate from this tick species during the last 60 years. Nearly half of the capybara population of the residential park was seroreactive to $R$. rickettsii, corroborating the findings that the local $A$. cajennense population was infected by $R$. rickettsii.

\section{Competing interests}

The authors declare that they have no competing interests.

\section{Authors' contributions}

FSK performed tick field study, lab experiments, processed the data, and drafted the manuscript. FAN-B and JFS conducted lab experiments, processed the data, and revised the manuscript. FPN performed capybara field study and revised the manuscript. MBL contributed to study design, field study, data analysis and interpretation, and revised the manuscript. All authors read and approved the final manuscript.

\section{Acknowledgments}

We are grateful to the administrative staff of the residential park that provided logistic support for the present study, and to the "Superintendência de Controle de Endemias" of the state of São Paulo (SUCEN) for their valuable help in collecting ticks. This work was supported by the Brazilian funding agencies FAPESP, CNPq, and CAPES

\section{Author details}

'Department of Preventive Veterinary medicine and animal Health, Faculty of Veterinary Medicine, University of São Paulo, São Paulo, SP 05508-270, Brazil. ${ }^{2}$ Veterinary and Technical Responsible by the Association Fazenda Vila Real de Itu - Rodovia Marechal Rondon Km 113.5, Itu, SP 13312-901, Brazil.

Received: 23 October 2013 Accepted: 1 January 2014

Published: 5 January 2014

\section{References}

1. Del Fiol FS, Junqueira FM, Rocha MCP, Toledo MI, Filho SB: Febre maculosa no Brasil. Rev Panam Salud Publica 2010, 27:461-466.

2. Chapman AS, Bakken JS, Folk SM, Paddock CD, Bloch KC, Krusell A, Sexton DJ, Buckingham SC, Marshall GS, Storch GA, Dasch GA, McQuiston JH, Swerdlow DL, Dumler SJ, Nicholson WL, Walker DH, Eremeeva ME, Ohl CA, Tickborne Rickettsial Diseases Working Group: CDC: Diagnosis and management of tickborne rickettsial diseases: Rocky Mountain spotted fever, ehrlichioses, and anaplasmosis-United States: a practical guide for physicians and other health-care and public health professionals. MMWR Recomm Rep 2006, 55:1-27.

3. Eremeeva ME, Klemt RM, Santucci-Domotor LA, Silverman DJ, Dasch GA: Genetic analysis of isolates of Rickettsia rickettsii that differ in virulence. Ann N Y Acad Sci 2003, 990:717-722.

4. Karpathy SE, Dasch GA, Eremeeva ME: Molecular typing of isolates of Rickettsia rickettsii by use of DNA sequencing of variable intergenic regions. J Clin Microbiol 2007, 45:2545-2553.

5. Angerami RN, Resende MR, Feltrin AF, Katz G, Nascimento EM, Stucchi RS, Silva LJ: Brazilian spotted fever: a case series from an endemic area in southeastern Brazil: clinical aspects. Ann N Y Acad Sci 2006, 1078:252-254.

6. Parola P, Labruna MB, Raoult D: Tick-borne rickettsioses in America: unanswered questions and emerging diseases. Curr Infect Dis Rep 2009, 11(1):40-50

7. Ogrzewalska M, Saraiva DG, Moraes-Filho J, Martins TF, Costa FB, Pinter A, Labruna MB: Epidemiology of Brazilian spotted fever in the Atlantic Forest, state of São Paulo, Brazil. Parasitology 2012, 139(10):1283-1300.

8. Labruna MB: Ecology of rickettsia in South America. Ann N Y Acad Sci 2009, 1166:156-166.

9. Guedes E, Leite RC, Pacheco RC, Silveira I, Labruna MB: Rickettsia species infecting Amblyomma ticks from an area endemic for Brazilian spotted fever in Brazil. Rev Bras Parasitol Vet 2011, 20(4):308-311.
10. Pinter A, Labruna MB: Isolation of Rickettsia rickettsii and Rickettsia bellii in cell culture from the tick Amblyomma aureolatum in Brazil. Ann N Y Acad Sci 2006, 1078:523-529.

11. Labruna MB, Ogrzewalska M, Soares JF, Martins TF, Soares HS, Moraes-Filho J, Nieri-Bastos FA, Almeida AP, Pinter A: Experimental infection of Amblyomma aureolatum ticks with Rickettsia rickettsii. Emerg Infect Dis 2011, 17:829-834.

12. Soares JF, Soares HS, Barbieri AM, Labruna MB: Experimental infection of the tick Amblyomma cajennense, Cayenne tick, with Rickettsia rickettsii, the agent of rocky mountain spotted fever. Med Vet Entomol 2012 26:139-151.

13. Labruna MB: Brazilian spotted fever: the role of capybaras. In Capybara: Biology, Use and Conservation of an Exceptional Neotropical Species. Edited by Moreira JR, Ferraz KMPMB, Herrera EA, Macdonald DW. New York: Springer Science + Business Media; 2013:371-383

14. Souza CE, Moraes-Filho J, Ogrzewalska M, Uchoa FC, Horta MC, Souza SS, Borba RC, Labruna MB: Experimental infection of capybaras Hydrochoerus hydrochaeris by Rickettsia rickettsii and evaluation of the transmission of the infection to ticks Amblyomma cajennense. Vet Parasitol 2009 161:116-121.

15. Moreira JA, Magalhães O: Thypho exanthematico em Minas Gerais. Bras Med 1935, 44(21):465-470.

16. Dias E, Martins A, Ribeiro DJ: Thypho exanthematico no Oeste de Minas Gerais. Bras Med 1937, 51(24):651-655.

17. Vallejo-Freire A: Spotted fever in Mexico. Mem Inst Butantan 1946, 19:159-180.

18. Magalhães O: Contribuição ao conhecimento das doenças do grupo tifo exantematico. Rio de Janeiro: Instituto Oswaldo Cruz; 1952.

19. Guedes E, Leite RC, Prata MC, Pacheco RC, Walker DH, Labruna MB: Detection of Rickettsia rickettsii in the tick Amblyomma cajennense in a new Brazilian spotted fever-endemic area in the state of Minas Gerais. Mem Inst Oswaldo Cruz 2005, 100:841-845

20. Sangioni LA, Horta MC, Vianna MCB, Gennari SM, Soares RM, Galvão MAM Schumaker TTS, Ferreira F, Vidotto O, Labruna MB: Rickettsial infection in animals and Brazilian spotted fever endemicity. Emerg Infect Dis 2005 , 11:265-270

21. Estrada DA, Schumaker $\Pi$, Souza $C E$, Rodrigues Neto EJ, Linhares $A X$ : Rickettsiae detection in Amblyomma ticks (Acari: Ixodidae) collected in the urban area of Campinas City, SP. Rev Soc Bras Med Trop 2006, 39:68-71.

22. Pacheco RC, Horta MC, Pinter A, Moraes-Filho J, Martins TF, Nardi MS, Souza SSAL, Souza CE, Szabó MPJ, Richtzenhain LJ, Labruna MB: Pesquisa de Rickettsia spp. em carrapatos Amblyomma cajennense e Amblyomma dubitatum no Estado de São Paulo. Rev Soc Bras Med Trop 2009, 42:351-353.

23. Brites-Neto J, Nieri-Bastos FA, Brasil J, Duarte KMR, Martins TF, Veríssimo CJ Barbieri ARM, Labruna MB: Environmental infestation and rickettsial infection in ticks in a Brazilian spotted fever-endemic area. Rev Bras Parasitol Vet 2013, 22:367-372.

24. Aragão H: Ixodidas brasileiros e de alguns paizes limitrophes. Mem Inst Oswaldo Cruz 1936, 31:759-843.

25. Guglielmone AA, Beati L, Barros-Battesti DM, Labruna MB, Nava S, Venzal JM, Mangold AJ, Szabo MP, Martins JR, Gonzalez-Acuna D, Estrada-Pena A: Ticks (Ixodidae) on humans in South America. Exp Appl Acarol 2006, 40:83-100.

26. Oliveira PR, Borges LM, Lopes CM, Leite RC: Population dynamics of the free-living stages of Amblyomma cajennense (Fabricius, 1787) (Acari: ixodidae) on pastures of Pedro Leopoldo, Minas Gerais State, Brazil. Vet Parasitol 2000, 92:295-301.

27. Marrero M, Raoult D: Centrifugation-shell vial technique for rapid detection of Mediterranean spotted fever rickettsia in blood culture. Am J Trop Med Hyg 1989, 40:197-199.

28. Labruna MB, Whitworth T, Horta MC, Bouyer DH, McBride JW, Pinter A Popov V, Gennari SM, Walker DH: Rickettsia species infecting Amblyomma cooperi ticks from an area in the state of São Paulo, Brazil, where Brazilian spotted fever is endemic. J Clin Microbiol 2004, 42:90-98.

29. Roux V, Fournier PE, Raoult D: Differentiation of spotted fever group rickettsiae by sequencing and analysis of restriction fragment length polymorphism of PCR-amplified DNA of the gene encoding the protein rOmpA. J Clin Microbiol 1996, 34:2058-2065. 
30. Roux V, Raoult D: Phylogenetic analysis of members of the genus Rickettsia using the gene encoding the outer membrane protein rOmpB (ompB). Int J Syst Evol Microbiol 2000, 50:1449-1455.

31. Moreira JR, Ferraz KMPMB, Herrera EA, Macdonald DW: Capybara: Biology, Use and Conservation of an Exceptional Neotropical Species. New York: Springer Science + Business Media; 2013.

32. Patino-Camargo L: Nuevas observaciones sobre un tercer foco de fiebre petequial (maculosa) en el hemisferio americano. Bol De la Ofic Sanit Panamericana 1941, 20:1112-1124.

33. Bustamante ME, Varela G: Estudios de fiebre manchada en Mexico. Hallazgo del Amblyomma cajennense naturalmente infectado, en Veracruz. Rev Inst Salud Enf Trops 1946, 7:75-78.

34. Rodaniche EC: Natural infection of the tick Amblyomma cajennense with Rickettsia rickettsii in Panama. Am J Trop Med Hyg 1953, 2:696-699.

35. Péter $\mathrm{O}$, Raoult $\mathrm{D}$, Gilot $\mathrm{B}$ : Isolation by a sensitive centrifugation cell culture system of 52 strains of spotted fever group rickettsiae from ticks collected in France. J Clin Microbiol 1990, 28:1597-1599.

36. Kelly JP, Raoult D, Mason PR: Isolation of spotted fever group rickettsiae from triturated ticks using a modification of the centrifugation vial technique. Trans R Soc Trop Med Hyg 1991, 85:397-398.

37. Yu XJ, Walker DH: Genus Rickettsia da Rocha-Lima 1916. In Bergey's Manual of Systematic Bacteriology, Volume 2 Part C. 2nd edition. Edited by Brenner DJ, Krieg NR, Staley JR. New York: Springer; 2005:96-106.

38. Hidalgo M, Orejuela L, Fuya P, Carrillo P, Hernandez J, Parra E, Keng C, Small M, Olano JP, Bouyer D, Castaneda E, Walker D, Valbuena G: Rocky Mountain spotted fever, Colombia. Emerg Infect Dis 2007, 13:1058-1060.

39. Argüello AP, Hun L, Rivera P, Taylor L: A fatal urban case of Rocky Mountain spotted fever presenting an eschar in San Jose, Costa Rica. Am J Trop Med Hyg 2012, 87:345-348.

40. Katz G, Neves VLFC, Angerami RN, Nascimento EMM, Colombo S: Statistics and epidemiology of Brazilian spotted fever in São Paulo, Brazil. Boletim Epidemiológico Paulista 2009, 6:4-13.

41. Spencer RR, Parker RR: Rocky Mountain spotted fever: infectivity of fasting and recently fed ticks. Public Health Rep 1923, 38:333-339.

42. Gilford JH, Price WH: Virulent-avirulent conversions of Rickettsia rickettsii in vitro. Biochemistry 1955, 41:870-873.

43. Hayes SF, Burgdorfer W: Reactivation of Rickettsia rickettsii in Dermacentor andersoni ticks: an ultrastructural analysis. Infect Immun 1982, 37:779-785.

44. Burgdorfer W: The hemolymph test. Am J Trop Med Hyg 1970, 19:1010-1014

45. Vianna MC, Horta MC, Sangioni LA, Cortez A, Soares RM, Mafra CL, Galvão MA, Labruna MB, Gennari SM: Rickettsial spotted fever in Capoeirão village, Itabira, Minas Gerais, Brazil. Rev Inst Med Trop Sao Paulo 2008, 50:297-301.

46. Souza CE, Souza SSL, Lima VLC, Calic SB, Camargo MCGO, Savani ESMM, D'Auria SRN, Linhares AX, Yoshinari NH: Serological identification of Rickettsia spp from the spotted fever group in capybaras in the region of Campinas - SP - Brazil. Ciência Rural Santa Maria 2008, 38:1694-1699.

doi:10.1186/1756-3305-7-7

Cite this article as: Krawczak et al:: Rickettsial infection in Amblyomma cajennense ticks and capybaras (Hydrochoerus hydrochaeris) in a Brazilian spotted fever-endemic area. Parasites \& Vectors 2014 7:7.

\section{Submit your next manuscript to BioMed Central and take full advantage of:}

- Convenient online submission

- Thorough peer review

- No space constraints or color figure charges

- Immediate publication on acceptance

- Inclusion in PubMed, CAS, Scopus and Google Scholar

- Research which is freely available for redistribution

Submit your manuscript at www.biomedcentral.com/submit 